\title{
PERANCANGAN SISTEM INFORMASI AKUNTANSI PENYUSUTAN AKTIVA TETAP MENGGUNAKAN METODE GARIS LURUS PADA KOPKAR BINA KHATULISTIWA
}

\author{
Fatmawati Isnaini $^{1)}$, Fherna Aisyah ${ }^{2)}$, Dian Widiarti' ${ }^{3)}$, Donaya Pasha ${ }^{4)}$ \\ ${ }^{1), 2)}$ Sistem Informasi Akuntansi, Universitas Teknokrat Indonesia \\ ${ }^{3)}$ Universitas Abdurachman Saleh Situbondo \\ ${ }^{4)}$ Teknologi Informasi, Universitas Teknokrat Indonesia \\ Jl. H.ZA Pagaralam, No 9-11, Labuhanratu,Bandarlampung

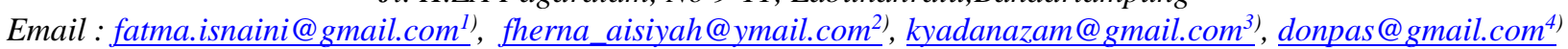

\begin{abstract}
Abstrak
Metode penyusutan garis lurus adalah salah satu metode yang paling banyak diaplikasikan oleh perusahaanperusahaan di Indonesia. Jumlah aktiva tetap yang dimiliki oleh KOPKAR Bina Khatulistiwa cukup banyak dan beragam, pembuatan laporan penyusutan aktiva tetap KOPKAR Bina Khatulistiwa dilakukan oleh karyawan bagian pembukuan. Perhitungan penyusutan aktiva tetap pada KOPKAR Bina Khatulistiwa dengan melakukan pencatatan pada Microsoft Excel. Masalah yang muncul dalam dalam laporan penyusutan dilakukan pada sheet yang berbeda sehingga membutuhkan waktu dalam pembuatan laporan. Selain itu laporan tidak disajikan berdasarkan aturan laporan yang baik. Dengan menggunakan aplikasi terkomputerisasi, karyawan bagian pembukuan dapat mengolah data penyusutan aktiva tetap yang akan menghasilkan laporan penyusutan yang dibutuhkan bagi pengguna. Selain itu, data penyusutan aktiva tetap dilaporkan oleh koordinator dalam RUPS untuk menilai penyusutan aktiva tetap sebagai oposional dan aset perusahaan yang mengeluarkan biaya.
\end{abstract}

Kata kunci: aktiva tetap, garis lurus, sistem informasi, penyusutan.

\section{Pendahuluan}

Aktiva tetap merupakan bagian terpenting dalam suatu perusahaan baik ditinjau dari segi fungsinya, jumlah dana yang diinvestasikan, maupun pengawasannya. Aktiva tetap adalah salah satu bagian yang juga terdapat dalam laporan keuangan yaitu ada didalam neraca (Laelisneni, 2014). Setiap bentuk badan usaha yang ada saat ini mulai dari yang berukuran kecil hingga yang besar pasti akan memanfaatkan aset tetap yang dimilikinya. Berjalannya waktu nilai suatu aktiva tetap harus dapat disusutkan atau dibebankan secara tepat dan salah satu caranya adalah dengan menggunakan metode penyusutan (Mairuhu \& Tinangon, 2014). Sesuai dengan yang tercantum dalam Pernyataan Standar Akuntansi Keuangan (PSAK) Nomor 16 (revisi 2011) tentang akuntansi penyusutan, penyusutan adalah alokasi sistematis jumlah yang dapat disusutkan dari suatu aset selama umur manfaatnya. Adanya perhitungan penyusutan dapat berpengaruh pada laporan keuangan perusahaan. Penghitungan beban penyusutan sangat penting bagi perusahaan karena pengakuan beban penyusutan setiap tahun dapat digunakan sebagai alokasi perusahaan untuk membeli aktiva baru jika umur ekonomis aktiva lama telah habis. Biaya penyusutanakan mempengaruhi harga pokok penjualan dan beban usaha yang akan mempengaruhi besarnya laba yang diperoleh perusahaan. Metode penyusutan garis lurus adalah salah satu metode yang paling banyak diaplikasikan oleh perusahaan-perusahaan di Indonesia. Dalam metode penyusutan garis lurus, beban penyusutan untuk tiap tahun nilainya sama besar dan tidak dipengaruhi dengan hasil atau output yang berproduksi (Arniati \& Windariyani, 2013).

KOPKAR Bina Khatulistiwa merupakan koperasi yang dibangun untuk memajukan kesejahteraan karyawan PT. Biru Laut Khatulistiwa. Dengan adanya koperasi karyawan, kebutuhan karyawan dapat diperoleh di koperasi. Seperti pada umumnya KOPKAR Bina Khatulistiwa memiliki aktiva tetap yang digunakan dalam kegiatan operasional koperasi. Jumlah aktiva tetap yang dimiliki oleh KOPKAR Bina Khatulistiwa cukup banyak dan beragam, pembuatan laporan penyusutan aktiva tetap KOPKAR Bina Khatulistiwa menggunakan metode garis lurus dan dilakukan oleh karyawan bagian pembukuan. Bagian pembukuan memperoleh nota pembelian aktiva tetap dari kasir, yang kemudian dibuatkan voucher pengeluaran kas yang dilampirkan pada nota tersebut. Perhitungan penyusutan aktiva tetap pada KOPKAR Bina Khatulistiwa dengan melakukan pencatatan pada Microsoft Excel. Aktiva tetap dikelompokan berdasarkan unit usaha yang ada di KOPKAR Bina Khatulistiwa, pada saat pembuatan laporan keuangan pada periode tertentu dilakukan perhitungan penyusutan menggunakan metode garis lurus. Masalah yang muncul dalam dalam laporan penyusutan dilakukan pada sheet yang berbeda pada Microsoft Excel sehingga membutuhkan waktu dalam pembuatan laporan. Selain itu laporan tidak disajikan berdasarkan aturan laporan yang baik. Untuk itu perlu adanya sistem informasi akuntansi yang mengelola penyusutan aktiva tetap menggunakan metode garis lurus 
sehingga dapat menyajikan laporan yang dapat mempermudah dalam pengambilan keputusan.

\section{Pembahasan}

\subsection{Analisis Sistem Berjalan}

Prosedur pengelolaan penyusutan aktiva tetap yang berjalan adalah sebagai berikut:

1. Pegawai bagian pembukuan menerima nota pembelian aktiva tetap dari kasir.

2. Berdasarkan nota yang diperoleh bagian pembukuan membuat voucher pengeluaran kas sebanyak dua rangkap.

3. Voucher pengeluaran kas dua rangkap beserta nota pembelian aktiva tetap diserahkan kepada koordinator koperasi untuk ditandatangani.

4. Voucher pengeluaran kas rangkap pertama disimpan dibagian koordinator, sedangkan voucher pengeluaran kas rangkap pertama beserta nota pembelian aktiva tetap dikembalikan kebagian pembukuan.

5. Bagian pembukuan membuat laporan penyusutan aktiva tetap sebanyak dua rangkap berdasarkan voucher pengeluaran kas dan nota pembelian yang sudah ditandatangani.

6. Nota pembelian dan voucher pengeluaran kas diarsip berdasarkan tanggal dibagian pembukuan.

7. Laporan penyusutan aktiva tetap dua rangkap diserahkan kepada koordinator untuk dicek, jika laporan sudah sesuai dengan voucher pembelian maka ditandatangani. Jika tidak maka dikembalikan kebagian pembukuan.

8. Laporan penyusutan aktiva tetap dua rangkap yang sudah ditandatangi dikembalikan kebagian pembukuan.

9. Laporan penyusutan aktiva tetap rangkap pertama diarsip dibagian pembukuan berdasarkan tanggal, sedangakan rangkap kedua diserahkan kepada ketua koperasi.

\subsection{Analisa Kebtuhan}

Analisis kebutuhan merupakan proses mendapatkan informasi, model, spesifikasi sistem yang diinginkan pengguna (Simarmata, 2010). Analisis kebutuhan menentukan apa yang harus dilakukan sistem dan mendefinisikan batasan batasan operasi dan implementasinya agar dapat mengomunikasikan secara tepat semua fungsi yang diberikan (Sommervile, 2011). Analisis kebutuhan dibagi menjadi dua, kebutuhan fungsional dan kebutuhan nonfungsional.

\subsubsection{Analisa Kebutuhan Fungsional}

Analisis kebutuhan fungsional merupakan pernyataan layanan yang harus diberikan kepada sistem agar dapat melakukan keperilakuannya dalam bereaksi terhadap masukan tertentu (Kosasi \& Kuway, 2012). Berdasarkan dari analisis kebutuhan maka ada beberapa kebutuhan fungsional yang ada di dalam suatu sistem. Dalam kebutuhan fungsional ini, aplikasi yang dirancangan sesuai dengan kebutuhan yang diharapkan dapat berjalan pada KOPKAR Bina Khatulistiwa. Berikut kebutuhan fungsional yang dapat dilihat dibawah ini:

1. Aplikasi dapat memberikan laporan kepada ketua koperasi

2. Aplikasi dapat melakukan penginputan data aktiva tetap kedalam database dan melakukan perhitungan penyusutan.

\subsubsection{Analisa Kebutuhan Non-Fungsional}

Analisis kebutuhan non-fungsional merupakan kebutuhan yang berisi tentang batasan layanan atau fungsi yang diberikan system (Kosasi \& Kuway, 2012). Dengan ditemukannya permasalahan yang terjadi pada sistem penyusutan aktiva tetap pada KOPKAR Bina Khatulistiwa, maka diusulkan untuk pengembangan sistem menggunakan sistem terprogram untuk mengelola penyusutan aktiva tetap menggunakan Java Netbeans 8.0.1 dan Database MySQL yang diharapkan dapat mempermudah dan mempercepat proses pengelolaan data penyusutan aktiva tetap. Kebutuhan non fungsional dapat dilihat dibawah ini:

1. Perangkat Keras
a. Processor dengan kecepatan $2.0 \mathrm{GHz}+$ Motherboard
b. VGA card $128 \mathrm{MB}$
c. Memory $2 \mathrm{~GB}$
d. Hard Disk space 80GB terpasang
e. Monitor
f. Mouse
g. Keyboard

Berdasarkan analisis perangkat keras diatas spesifikasi komputer yang ada sangat mencukupi, hanya saja perlu printer standar untuk mencetak laporan.

\section{Perangkat Lunak}

Selain perangkat keras, untuk membuat sistem pengolahan data aktiva tetap dibutuhkan spesifikasi perangkat lunak yang digunakan sebagai pendukung sistem adapun spesifikasi perangkat lunak yang digunakan adalah:

1. Sistem Operasi Windows 7

2. Java Netbeans 8.0.1

3. MYSQL Database

\subsection{Perhitungan Penyusutan}

Berikut adalah contoh soal penyusutan aktiva tetap metode garis lurus yang digunakan oleh KOPKAR Bina Khatulistiwa:

1. PC P4-1.6Mhz

Harga Perolehan

Nilai Residu : Rp. 5.750 .000

Umur Ekonomis

$: 0$

Persentase

: 5 Tahun

Cara penyelesaian:

$=($ Harga perolehan-Nilai residu $) /$ Umur Ekonomis

$=($ Rp. 5.750.000-Rp. 0) / 5 Tahun

$=$ Rp. 1.150 .000 
2. Pesawat Telepon

Harga Perolehan

Nilai Residu

: Rp. 385.500

Umur Ekonomis

$: 0$

: 5 Tahun

: $100 / 4(0.25 \%)$

Persentase

$=($ Harga perolehan-Nilai residu $) /$ Umur ekonomis

$=($ Rp. 385.500-Rp. 0) / 5 Tahun

$=$ Rp. 77.100

3. DP Aplikasi Program

Harga Perolehan

: Rp. 2.505.000

Nilai Residu

$: 0$

Umur Ekonomis

: 5 Tahun

Persentase

: 100/4 (0.25\%)

Cara penyelesaian:

$=($ Harga perolehan-Nilai residu $) /$ Umur ekonomis

$=($ Rp. 2.505.000-Rp. 0) $/ 5$ Tahun

$=$ Rp. 501.000

4. Installasi Jaringan

Harga Perolehan

Nilai Residu

: Rp. 1.795 .000

Umur Ekonomis

$: 0$

Persentase

: 5 Tahun

: $100 / 4(0.25 \%)$

Cara penyelesaian:

$=($ Harga perolehan-Nilai residu $) /$ Umur ekonomis

$=($ Rp. 1.795.000-Rp. 0) / 5 Tahun

$=$ Rp. 359.000

5. Perangkat Backup

Harga Perolehan

Nilai Residu

: Rp. 2.750 .000

Umur Ekonomis

$: 0$

: 5 Tahun

Persentase

: 100/4 (0.25\%)

Cara penyelesaian:

$=($ Harga perolehan - Nilai residu $) /$ Umur ekonomis

$=($ Rp. 2.750.000-Rp. 0) $/ 5$ Tahun

$=$ Rp. 550.000

Tabel 1. Daftar Penyusutan Aktiva Tetap

\begin{tabular}{|c|c|c|c|c|c|c|c|c|}
\hline Kode & Tahun & Satuan & Nama Barang & Ekomomis & $\begin{array}{l}\text { Persentasi } \\
\end{array}$ & Nilai Perolehan & Beban Penyusutan & Nilai Buku \\
\hline KA00001 & 2016 & I Unit & PC P41.6 Mhz. & 5 & 0.2 & $\operatorname{Rp} 5,750,000.00$ & $\operatorname{Rp} 1,150,000.00$ & Rp $4,600,000.00$ \\
\hline KA00005 & 2016 & 1 Unit & Pesswat telepon & 5 & 0.2 & $R_{p} 385,500.00$ & Rpp77,100.00 & $\operatorname{Rp} 308,400.00$ \\
\hline KA00004 & 2016 & 1 Set & DP Aplikasi program & 5 & 0.2 & $\operatorname{Rp} 2,505,000.00$ & Rp501,000.00 & Rp2, 2,040,000.00 \\
\hline KA00003 & 2016 & 1 Unit & Installasi Jaringan & 5 & 0.2 & $\operatorname{Rp} 1,795,000.00$ & Rp 359,000.00 & $\operatorname{Rpp} 1,436,000.00$ \\
\hline KA00002 & 2016 & 1 Unit & Perangakat Backup \& & 5 & 0.2 & $\operatorname{Rp} 2,750,000.00$ & Rp 550,000.00 & $R_{p} 2,200,000.00$ \\
\hline \multicolumn{6}{|c|}{ TOTAL. } & $\operatorname{Rpp} 13,185,500.00$ & $\operatorname{Rp} 2,637,100,00$ & $\operatorname{Rp} 10,548,400.00$ \\
\hline
\end{tabular}

\subsection{Ayat Jurnal Penyesuaian}

Jurnal penyesuaian dibuat pada akhir periode akuntansi setelah penyusunan neraca saldo dan sebelum penyusunan kertas kerja (worksheet).Jurnal penyesuaian dibuat untuk menyesuaikan angka-angka yang tersebut dalam neraca saldo agar dapat menggambarkan keadaan yang sebenarnya sesuai dengan tuntutan dalam penyajian laporan keuangan.Ayat jurnal penyesuaian penyusutan aktiva tetap pada KOPKAR Bina Khatulistiwa dapat dilihat pada tabel 2 berikut ini:
Tabel 2. Ayat Jurnal Penyesuaian

\begin{tabular}{|c|c|c|c|c|c|c|}
\hline Kode & Tahun & & a Akun & & Debit & Kredit \\
\hline KPOOOO1 & 2016 & PC & & & $1,150,000$ & \\
\hline & & Monitor & & & 275,000 & \\
\hline KPOOOO2 & 2016 & & Monitor & & & 275,000 \\
\hline КРОоOоз & 2017 & PC & PS & & $1,150,000$ & 15000 \\
\hline KPOOOO4 & 2017 & Monitor & & & 275,000 & \\
\hline KPOOOOO4 & 2017 & & Monitor & & 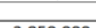 & 275,000 \\
\hline
\end{tabular}

\subsection{Desain Pengguna}

Tahap ini bertujuan untuk memberikan gambaran apa yang seharusnya dikerjakan dan bagaimana tampilannya (Damayanti \& Sulistiani, 2017). UML (unified Modelling Language) adalah Bahasa visual untuk pemodelan dan komunikasi mengenai sebuah sistem dengan menggunakan diagram dan teks-teks pendukung (Pressman, 2012). Pada penelitian ini desain system digambarkan dengan Use Case Diagram. Use case diagram atau diagram use case merupakan pemodelan untuk prilaku (behaviour) sistem informasi yang akan dibuat (Melinda et al., 2017). Diagram ini akan mendeskripsikan apa yang akan dilakukan oleh system (Rulyana \& Borman, 2014). Terdapat dua aktor yang menjalakan sistem yaitu bagiam pembukuan dan koordinator KKBK. Diagram usecase sistem penyusutan aktiva tetap metode garis lurus dapat dilihat pada gambar 1 dibawah ini:

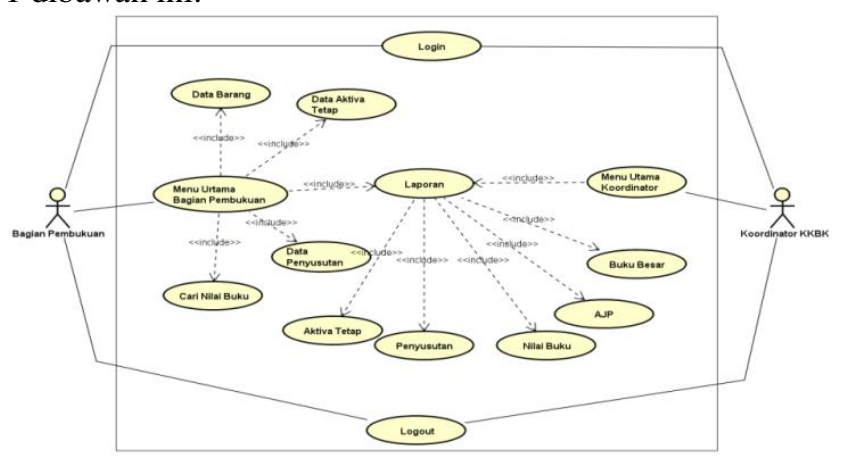

Gambar 1. Use Case Diagram Perancangan Sistem Informasi Akuntansi Penyusutan Aktiva Tetap Metode Garis Lurus

\subsection{Implementasi Program}

Menggunakan sistem merupakan tahap mengoprasikan sistem. Tahap penggunaan sistem ini dilakukan setelah sistem selesai, kemudian peneliti melaksanakan pelatihan terhadap petugas yang akan menggunakan sistem, dengan memberi pengertian dan pengetahuan yang cukup tentang sistem informasi, posisi dan tugas setiap fungsi. Pelatihan ini untuk petugas yang akan mengoperasikan sistem, yaitu bagian pembukuan. Hal ini dimaksudkan agar user memahami prosedur kerja sistem, dapat mengurangi kesalahan-kesalahan yang timbul yang dapat menghambat kelancaran operasional perusahaan, sehingga tujuan sistem dapat tercapai. Pada sistem informasi akuntansi penyusutan aktiva tetap menggunakan metode garis lurus pada KOPKAR Bina 
Khatulistiwa pada aplikasi yang telah dikembangkan proses pengolahan data dilakukan pada form-form yang telah sediakan antara lain form data barang, form data aktiva tetap dan form data penyusutan,

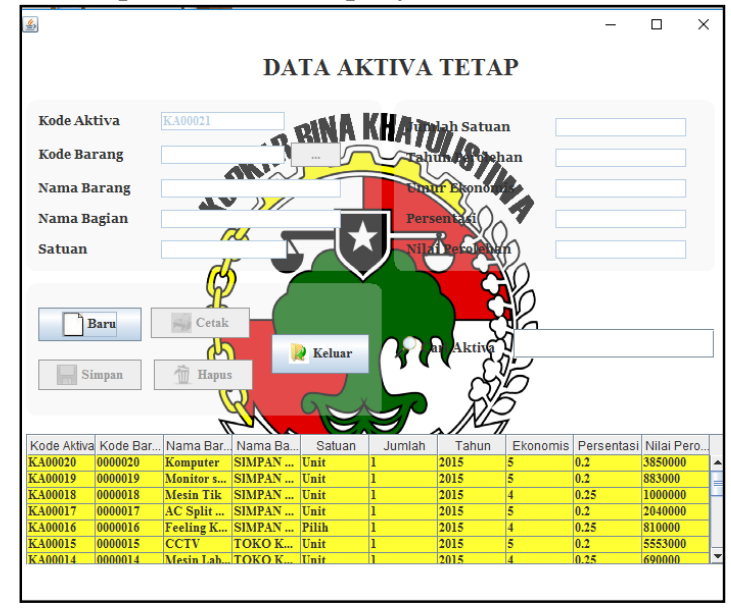

Gambar 2. Form Data Aktiva Tetap

Untuk menghitung nilai penyusutan suatu aktiva tetap dapat dilakukan pada form data penyusutan seperti pada gamar 3 berikut ini.

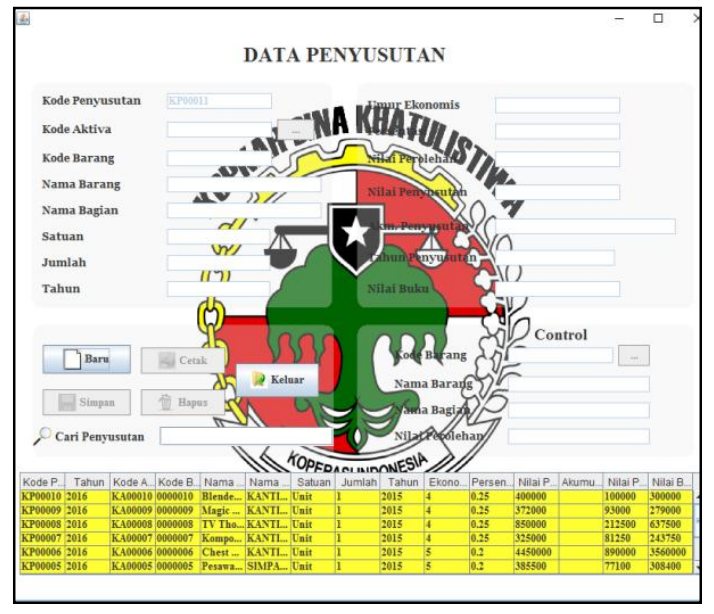

Gambar 3. Form Data Aktiva Tetap

Untuk laporan aplikasi ini menyajikan laporan diantaranya laporan aktiva tetap, laporan penyusutan, laporan nilai, laporan ayat jurnal penyesuaian dan form laporan buku besar.

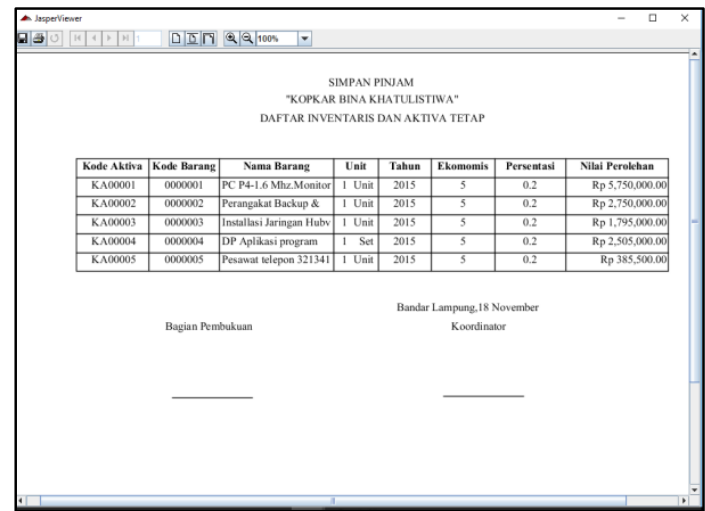

Gambar 4. Output Laporan Aktiva Tetap
Laporan penyusutan disajikan sesuai dengan kaidah laporan penyusutan dengan menyajikan nilai perolehan, beban penyusutan dan nilai baku

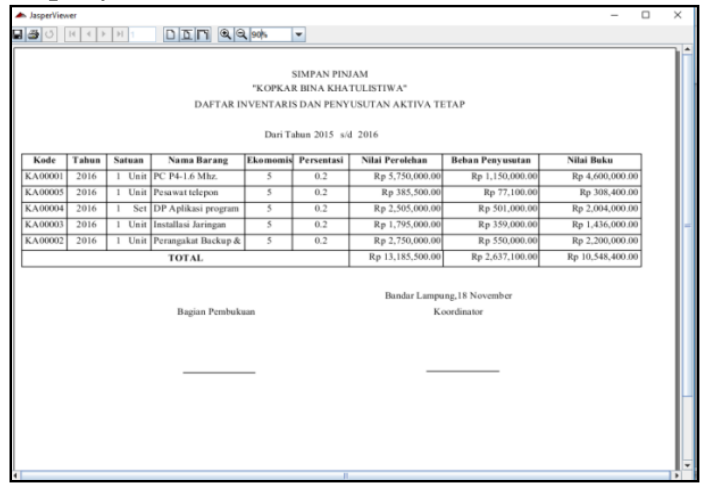

Gambar 5. Output Laporan Penyusutan

\section{Kesimpulan}

Hasil dari perancangan sistem informasi akuntansi penyusutan aktiva tetap metode garis lurus pada KOPKAR Bina Khatulistiwa, maka dapat ditarik simpulan dengan menggunakan aplikasi terkomputerisasi, karyawan bagian pembukuan dapat mengolah data penyusutan aktiva tetap yang akan menghasilkan laporan penyusutan yang dibutuhkan bagi pengguna. Selain itu, data penyusutan aktiva tetap dilaporkan oleh koordinator dalam RUPS untuk menilai penyusutan aktiva tetap sebagai oposional dan aset perusahaan yang mengeluarkan biaya.

\section{Daftar Pustaka}

Arniati \& Windariyani, F., 2013. Penerapan Konsep Nilai Waktu Uang Pada Penyusutan Aktiva Tetap dan Pengaruhnya Terhadap Kewajiban Pajak pada PT Synergy Indonesia. Jurnal Akuntansi, Ekonomi dan Manajemen Bisnis, 3(1).

Damayanti \& Sulistiani, H., 2017. Sistem Informasi Pembayaran Biaya Sekolah Pada SD Ar-Raudah Bandar Lampung. Jurnal TEKNOINFO, 11(2).

Kosasi, S. \& Kuway, S.M., 2012. Studi Analisis Persyaratan Kebutuhan Sistem Dalam Menghasilkan Perangkat Lunak Yang Berkualitas. Jurnal Ilmiah SISFOTENIKA, 2(1).

Mairuhu, S. \& Tinangon, J.J., 2014. Analisis Penerapan Metode Penyusutan Aktiva Tetap Dan Implikasinya Terhadap Laba Perusahaan Pada Perum Bulog Divre Sulut Dan Gorontalo. Jurnal $E M B A, 2(4)$.

Melinda, M., Borman, R.I. \& Redy, E.S., 2017. Rancang Bangun Sistem Informasi Publik Berbasis Web (Studi Kasus : Desa Durian Kecamatan Padang Cermin Kabupaten Pesawaran). Jurnal TEKNO KOMPAK, 11(1).

Pressman, R.S., 2012. Rekayasa Perangkat Lunak. Yogyakarta.

Rulyana, D. \& Borman, R.I., 2014. Aplikasi Simulasi Tes Potensi Akademik Berbasis Mobile Platform 
Android. In Seminar Nasional FMIPA-Universitas Terbuka. DKI Jakarta, 2014.

Simarmata, J., 2010. Rekayasa Perangkat Lunak.

Yogyakarta: Andi Publisher.

Sommervile, I., 2011. Software Engineering Ninth. Addison-Wesley. 